\title{
Inhibition of the alpha- $v$ integrins with a cyclic RGD peptide impairs angiogenesis, growth and metastasis of solid tumours in vivo
}

\author{
MA Buerkle', SA Pahernik', A Sutter², A Jonczyk², K Messmer' and M Dellian*,1,3 \\ 'Institute for Surgical Research, Klinikum Grosshadern, Marchioninistrasse 15, Ludwig-Maximilians-University, 81 377 Munich, Germany; ${ }^{2}$ Merck KGaA \\ Preclinical Research, Frankfurter Strasse 250, D-6427 Darmstadt, Germany; ${ }^{3}$ Department of Otorhinolanyngology, Klinikum Grosshadern, \\ Marchioninistrasse 15, Ludwig-Maximilians-University, 81377 Munich, Germany
}

Anti-angiogenetic cancer therapy is a potential new form for treatment of solid tumours. The $\alpha_{v}$-integrins $\left(\alpha_{v} \beta_{3}, \alpha_{v} \beta_{5}\right)$ mediate the contact of activated endothelial cells to proteins of the extracellular matrix during tumour angiogenesis as a prerequisite for survival of endothelial cells. The aim of this study was to investigate the effects of application of a methylated cyclic RGDpeptide as an $\alpha_{v}$-integrin antagonist on angiogenesis, microcirculation, growth and metastasis formation of a solid tumour in vivo. Experiments were performed in the dorsal skinfold preparation of Syrian Golden hamsters bearing the amelanotic hamster melanoma A-Mel-3. Animals were injected intraperitoneally with a methylated cyclic RGD-peptide every 12 h, the control group received an inactive peptide. Microcirculatory parameters of tumour angiogenesis including functional vessel density, red blood cell velocity, vessel diameter and leucocyte-endothelium interaction were analysed using intravital microscopy. In an additional study the effects on growth and metastasis of subcutaneous A-Mel-3 were quantified. Functional

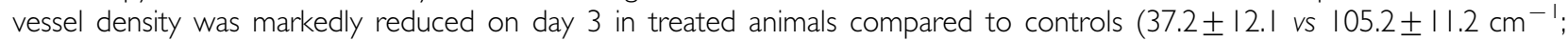
mean \pm s.e.m.; $P<0.05)$ and increased subsequently in both groups. Red blood cell velocity at day 3 was below values of controls $\left(0.026 \pm 0.01\right.$ vs $\left.0.12 \pm 0.03 \mathrm{~mm} \mathrm{~s}^{-1} ; P<0.05\right)$. No differences were observed in vessel diameters and leucocyteendothelium interaction was almost absent in both groups. Furthermore, growth and metastasis of subcutaneous tumours after administration of the cyclic RGD-peptide was significantly delayed in comparison to controls $(P<0.05)$. Inhibition of $\alpha_{v}{ }^{-}$ integrins by a cyclic RGD-peptide resulted in significant reduction of functional vessel density, retardation of tumour growth and metastasis in vivo. Taken together, these results implicate RGD-peptides as agents which have anti-tumour and antimetastatic activity in vivo.

British Journal of Cancer (2002) 86, 788-795. DOI: 10.1038/sj/bjc/6600I4I www.bjcancer.com

(C) 2002 Cancer Research UK

Keywords: angiogenesis; tumour; antiangiogenesis; $\alpha_{v}$-integrins; RGD-peptides

\begin{abstract}
Angiogenesis, the growth of new blood vessels from pre-existing vessels, is involved in several physiological and pathological situations like wound healing (Clark et al, 1982) and inflammatory diseases (Auerbach and Auerbach, 1994; Folkman, 1995). For growth and metastasis of solid tumours angiogenesis is the key prerequisite (Folkman, 1990, 1995). Furthermore, the extent of vascularisation in solid tumours is an independent prognostic factor for survival and therapeutic outcome (Weidner et al, 1991, 1993; Graham et al, 1994). Recently, the concept of anti-angiogenetic therapy for tumours has been proven in animals (O'Reilly et al, 1997), and this new therapeutic strategy will most likely gain clinical importance. However, development of anti-angiogenetic drugs based on the understanding of the mechanisms of angiogenesis is still in the early stages.

There is emerging evidence that tumour angiogenesis is regulated by the balance of pro-angiogenic and anti-angiogenic factors (Liotta et al, 1991; Hanahan and Folkman, 1996). To
\end{abstract}

*Correspondence: M Dellian; E-mail: dellian@icf.med.uni-muenchen.de Received I8 December 2000; revised II October 200 I; accepted 29 November 200। establish a vascular system in the tumour it requires the cooperation of a variety of molecules that regulate cellular processes such as activation of endothelial cells, proliferation, modulation of the extracellular matrix (ECM), invasion, migration and vascular remodelling. Members of the integrin class of cell adhesion receptors play a key role in cell-cell and cell-ECM interaction during the growth of new blood vessels (Hynes, 1992; Luscinskas and Lawler, 1994). Especially the $\alpha_{\mathrm{v}}$-integrins, combined with distinct $\beta$ subunits, exhibit a high expression in angiogenesis (Cheresh, 1992; Eliceiri and Cheresh, 1999). $\alpha_{\mathrm{v}}$-integrins on endothelial cells are capable of recognising a variety of ECM proteins with an exposed Arg-Gly-Asp (RGD) sequence, including vitronectin, fibronectin, fibrinogen, thrombospondin, proteolysed collagen, von Willebrand factor and osteopontin (Brooks, 1996). Consequently, antibodies or synthetic RGD-containing peptides directed against the $\alpha_{\mathrm{v}}$-integrins inhibited in vitro endothelial tube formation or microvessel outgrowth in previous experiments (Nicosia and Bonanno, 1991; Brooks, 1996; Bayless et al, 2000). Most recently it was shown that the expression of $\alpha_{\mathrm{v}} \beta_{3}$ and $\alpha_{\mathrm{v}} \beta_{5}$ by the microvascular endothelium of neuroblastoma is associated with the aggressiveness of these tumours (Erdreich-Epstein et al, 2000). 
The importance of $\alpha_{\mathrm{v}}$-integrins in tumour angiogenesis was especially elucidated by Cheresh and colleagues in a series of experiments (Brooks et al, 1994a,b). An anti- $\alpha_{v} \beta$-mAb limited blood vessel growth of human melanomas, implanted in the chorioallantoic membrane (Brooks et al, 1994b). Application of cyclic RGD peptide antagonists for $\alpha_{\mathrm{v}} \beta_{3}$ and $\alpha_{\mathrm{v}} \beta_{5}$ disrupted angiogenesis on the CAM and lead to regression of transplanted tumours (Brooks et al, 1994a). Interestingly, the antagonists did not affect pre-existing vessels. The mechanism of action of $\alpha_{\mathrm{v}}$-antagonists in blocking angiogenesis seems to be related to their ability to selectively promote apoptosis of endothelial cells in newly sprouting blood vessels (Brooks et al, 1994b; Stromblad et al, 1996; Eliceiri and Cheresh, 1999) and by affecting the function of proteolytic enzymes such as metalloproteinases (Brooks et al, 1996; 1998).

Recently, a methylated cyclic RGD peptide has been synthesised as highly active and selective ligand for the $\alpha_{\mathrm{v}}$-integrin receptor (Dechantsreiter et al, 1999). The effects of anti-angiogenic treatment using this cyclic RGD-peptide on growth and angiogenesis of solid tumours in vivo have not been studied so far. The dorsal skinfold chamber preparation, bearing a solid homologous transplanted tumour, represents a unique and well established tool to study tumour angiogenesis non-invasively and continuously over a prolonged period of time in vivo (Asaishi et al, 1981; Endrich et al, 1982). Direct observation of tumour microvessels in the dorsal skinfold chamber preparation may provide further insights into the alterations of angiogenesis during the application of a potential angiogenesis inhibitor. It was therefore the aim of the present study to investigate the effects of the cyclic RGD peptide on tumour angiogenesis, microcirculation, growth and metastasis of solid tumours in vivo.

\section{MATERIALS AND METHODS}

Experiments were performed with male Syrian Golden Hamsters (6-8 weeks old, 50-60 g body weight (bw)) in accordance with institutional guidelines after approval of the animal committee of the Bavarian state. The animals were housed one per cage and had free access to tap water and standard laboratory food throughout the experiments. Animals were inspected at least two times a day by specialised animal colony staff to assure a normal clinical condition (including appearance, posture, behaviour and physiological responses). Particular attention was given to body weight and any signs of discomfort, ulceration or inflammation. All surgical procedures were performed under pentobarbital anaesthesia (50 $\mathrm{mg} \mathrm{kg}^{-1}$ b.w., i.p.; Nembutal, Sanofia-Leva, Hannover, Germany). The experiments met all the standards required by the UKCCCR guidelines for the welfare of animals in experimental neoplasia (United Kingdom Co-ordinating Committee on Cancer Research (UKCCCR), 1998).

\section{Dorsal skinfold chamber preparation}

For quantification of tumour angiogenesis, a dorsal skinfold chamber preparation consisting of two symmetrical titanium frames was surgically implanted into the dorsal skin as described earlier in detail (Asaishi et al, 1981; Endrich et al, 1982). This is considered to cause the least distress upon the animal because the dorsal skin is extremely expansible. Following implantation of the transparent chamber and a recovery period of $48 \mathrm{~h}$ from anaesthesia and microsurgery, preparations fulfilling the criteria of an intact microcirculation were implanted with $2 \times 10^{5}$ cells of the amelanotic melanoma of the hamster A-Mel-3 (Fortner et al, 1961). Fine polyethylene catheters (PE10, inner diameter $0.28 \mathrm{~mm}$ ) were permanently inserted into the right jugular vein $48 \mathrm{~h}$ before first measurement to allow injection of fluorescent agents for intravital fluorescence microscopy. The animals tolerated the dorsal skinfold chamber well and showed no signs of discomfort.

\section{Assessment of tumour angiogenesis and growth by intravital microscopy}

Quantification of tumour angiogenesis using intravital fluorescence microscopy have been described in detail elsewhere (Asaishi et al, 1981; Dellian et al, 1995, 1996). In brief, the awake animal was trained to crawl into a transparent plastic tube and was placed on a custom-made stage under a modified Leitz microscope (Orthoplan; Leitz, Munich, Germany). FITC-labelled dextran (Sigma, Deisenhofen, Germany; MW 500000; 0.05-0.1 ml of a $5 \%$ solution in $0.9 \% \mathrm{NaCl}$ ) as a plasma marker and rhodamine 6G (Molecular Probes, Eugene, OR, USA; $0.04 \mathrm{ml}$ of a $0.05 \%$ solution in $0.9 \% \mathrm{NaCl}$ ) to label white blood cells in vivo, were injected i.v. to visualise microcirculation and leucocyte - endothelium interaction, respectively. The used dosage of the applied fluorescence dye does not have any toxic effect upon the animal. Selective observation of FITC-labelled plasma was possible using epi-illumination with a $100 \mathrm{~W}$ mercury lamp attached to a Ploemopack illuminator with a Leitz I2/3 filter block (excitation 450-490 nm, emission $\leqslant 515 \mathrm{~nm}$ ) and rhodamine 6G-stained leucocytes were visualised using a Leitz N2 filter block (excitation 530-560 nm, emission $\leqslant 580 \mathrm{~nm}$ ). Intravital microscopy was performed 3, 5, 9 and 13 days after implantation of the tumour cells. At least 3-5 sites of interest per animal were randomly selected in centre and periphery of the tumour. Images were acquired by a SIT video camera (C2400-08; Hamamatsu Herrsching, Germany) and recorded on S-VHS video tape (Sony) for subsequent analysis. Parallel to microvascular observations the area covered by tumour in the chamber preparation was registered on videotape using a Leitz macroscope with video camera (XC-77; Sony) to evaluate tumour growth. The tumour area $\left(\mathrm{mm}^{2}\right)$ was quantified from videotape by digital image analysis.

Analysis of microcirculatory parameters was performed off-line from video tape by an image analysis system (Cap Image; Zeintl, Heidelberg, Germany). This system described in detail by Zeintl et al (1989) and Klyscz et al (1997) allows measurement of functional vessel density (FVD) as a parameter of angiogenic activity (Dellian et al, 1996). FVD is defined as the total length of perfused microvessels per unit area of observation and is given in $\mathrm{cm}^{-1}$. Red blood cell velocity (vRBC) was quantified with the line shift diagram method according to Klyscz et al (1997) in $\mathrm{mm} \mathrm{s}^{-1}$. Rolling leucocytes were defined as population of cells temporarily interacting with the vessel wall and thus having a velocity at least $50 \%$ below vRBC in the same vessel. Adherent leucocytes were given as the number of leucocytes remaining stationary for at least $30 \mathrm{~s}$ per square millimetre of vessel wall surface (Atherton and Born, 1972; Dellian et al, 1996).

\section{Evaluation of tumour growth and metastasis}

Male Syrian Golden Hamsters (weight, age and housing as described above) were anaesthetised with pentobarbital and the dorsal skin was shaven and chemically depilated (Pilcamed, Schwarzkopf, Germany). Cells (4 to $6 \times 10^{6}$ ) of the A-Mel-3 were suspended in a $10 \mu \mathrm{l}$ volume and injected s.c. over the lumbosacral region of the dorsal skin. This is considered to cause the least distress upon the animal because the dorsal skin is extremely expansible. Starting on day 5 after tumour cell implantation, the longer (l) and shorter (w) perpendicular axes and the height (h) of each tumour nodule were measured with callipers every other day. Metastases of the animals were determined by palpation of axillar and inguinal lymph nodes. The day when metastases were first palpable the animal was defined as metastasised. To minimise the pain and distress of the animals no biopsies were taken from the lymph nodes during the observation time. This was due to the known fact that the axillar or inguinal lymph nodes were the most frequent sites of metastasis formation (Fortner et al, 1961; Weiss et al, 1990). After the end of the experiments when animals 
were euthanised, biopsies were taken to confirm histologically the invasion of the lymph nodes. Tumour volume was calculated according to the formula $\mathrm{V}_{\mathrm{t}}=0.837 \times 1 \times \mathrm{w} \times \mathrm{h}$ (Weiss et al, 1990). Animals were observed for 15 to 17 days until tumours reached a maximum volume of $7 \mathrm{~cm}$. The A-Mel-3 tumour does not have severe side effects during this early period of growth.

\section{Treatment and experimental groups}

The cyclic integrin $\alpha_{\mathrm{v}}$ antagonist EMD121974 (cyclic Arg-Gly-AspD-Phe(N-methyl)Val) (Dechantsreiter et al, 1999) and the control peptide EMD135981 (cyclic Arg- $\beta$-Ala-Asp-D-Phe(N-methyl)Val) were synthesised and characterised at Merck KgAa (Darmstadt, Germany). In pilot studies pharmacokinetics of the peptides were compared after intravenous and intraperitoneal injection in hamsters. Plasma half-life time of the cyclic RGD-peptide after intraperitoneal injection was $47 \mathrm{~min}$, and the area under the curve was similar after intraperitoneal and intravenous administration. A subsequent pilot study demonstrated a slightly higher effect on tumour growth after administration of $30 \mathrm{mg} \mathrm{kg}^{-1}$ every $12 \mathrm{~h}$ compared to $30 \mathrm{mg}$ every 2 days. Therefore, we chose the following set-up for administration: Peptides were dissolved in PBS $\left(10 \mathrm{mg} \mathrm{ml} \mathrm{m}^{-1}\right)$. One day after implantation of tumour cells, animals were randomly assigned to two groups $(n=6)$ and RGD-peptide EMD121974 or control-peptide EMD135981 were given i.p. every $12 \mathrm{~h}\left(30 \mathrm{mg} \mathrm{kg}^{-1}\right.$ b.w.) until the end of the experiments.

\section{Statistical analysis}

Results are presented as mean \pm s.e.m. Data were evaluated using Wilcoxon-Mann-Whitney $U$ and Kruskal-Wallis test, respectively (SigmaStat; Jandel Scientific, San Rafael, CA, USA). Metastasis analysis was performed according to the Kaplan-Meier method (Kaplan and Meier, 1958) and the differences were compared for statistical significance using the Cox- $F$ test (Lee, 1975,1980 ) with the statistical software program Statistica (StatSoft, Inc, 1997, Tulsa, OK, USA). $P$ values smaller than $5 \%$ were considered to be significant.

\section{RESULTS}

\section{Functional vascular density}

Three days after tumour cell implantation intravital microscopy already revealed an early vascular network in controls (Figure 1). Short, thin-walled vessels building anastomosis and loops were characteristic for tumour vasculature at this day in the control group (Figure 1A). Intravital microscopy elicited early angiogenesis on day 3 in the RGD treated group. Sometimes vascular sprouts were visible without red cell perfusion (Figure 1B). Quantitative analysis confirmed these observations (Figure 2). Functional vessel density was significantly reduced on day 3 in treated animals in comparison to controls $\left(32.7 \pm 12.1\right.$ vs $105.2 \pm 11.2 \mathrm{~cm}^{-1}$; $P<0.05)$. Already on day 5, FVD of the control group reached the maximum value and decreased slightly thereafter until the end of the experiments (day 13). In the treated group the highest value of FVD was observed not before day 9, and stayed nearly at the same level afterwards. On day 13 after tumour implantation, FVD of controls was significantly below values of treated animals $\left(108.2 \pm 10.6\right.$ vs $\left.156.9 \pm 15.6 \mathrm{~cm}^{-1} ; P<0.05\right)$.

\section{RBC velocity, vessel diameter and leucocyte - endothelium interaction}

Similar to vessel density, RBC velocity (vRBC) in tumour vessels of treated animals was markedly below values of controls on day 3 $\left(0.026 \pm 0.01\right.$ vs $0.12 \pm 0.03 \mathrm{~mm} \mathrm{~s}^{-1} ; P<0.05$; Figure 3$)$. On days 9 and 13 , vRBC was slightly lower in treated animals than in

A

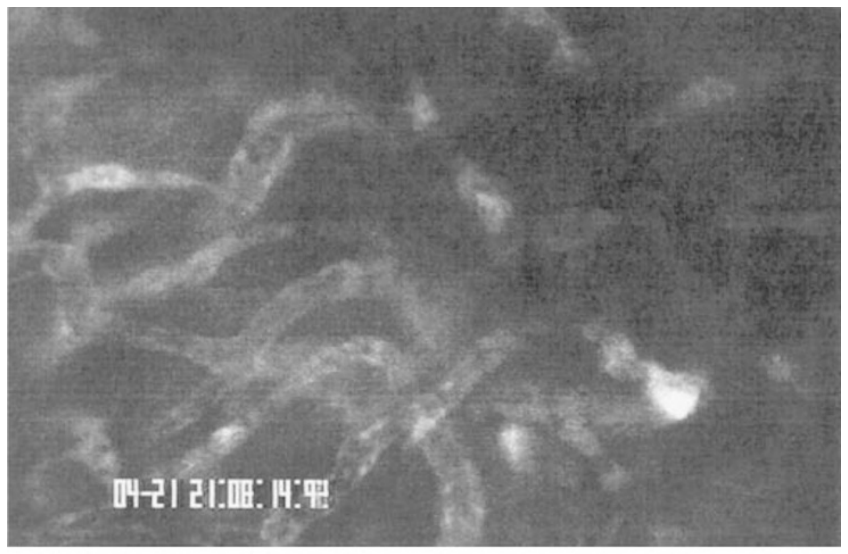

B

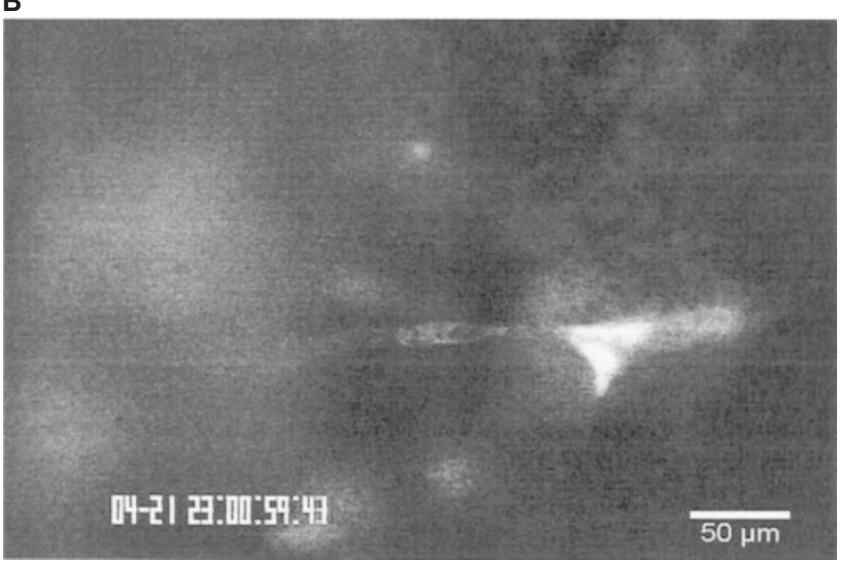

Figure I Images of tumour microcirculation 3 days after tumour cell implantation acquired by intravital microscopy after injection of the plasma marker FITC-Dextran. (A) Tumour vasculature of animals treated with the control peptide EMD 13598 I already appears as dense, chaotic structured network. (B) In the RGD peptide treated group (EMDI2 1974) only individual sprouts as signs of early angiogenesis were visible. Bar, $50 \mu \mathrm{m}$.

animals receiving the control peptide. Analysis of vessel diameters revealed no differences between animals treated with RGD peptide or control peptide (Figure 4). Leucocyte-endothelium interaction was almost absent in tumour microvessels of both groups.

\section{Tumour growth in the dorsal skinfold chamber}

In early tumour growth on day 5 the size of treated tumours was similar to controls (Figure 5A,B). After establishment of tumour microcirculation, rapid growth of the malignant tissue was possible (Figure 5C). In contrast, growth of the RGD treated tumour was delayed (Figure 5D). Quantitative data confirmed that treated tumours were slightly smaller than controls on days 3 and 5, tumour area was significantly reduced on days $9(20.5 \pm 1.4$ vs $\left.28.1 \pm 3.2 \mathrm{~mm}^{2} ; P<0.05\right)$ and $13\left(49.1 \pm 4.8\right.$ vs $80.94 \pm 6.1 \mathrm{~mm}^{2}$; $P<0.05$; Figure 6). Due to continuous growth, the tumours obscured the preparations in the control group after 13 days.

\section{Subcutaneous tumour growth and metastasis}

Quantitative data demonstrated that A-Mel-3 tumours treated with the control peptide EMD135981 showed nearly exponential growth (Figure 7). Administration of the $\alpha_{\mathrm{v}}$-antagonist EMD121974 delayed tumour growth for an average of $3.5 \pm 0.7$ days in comparison to controls: Volume of the treated tumours was significantly 


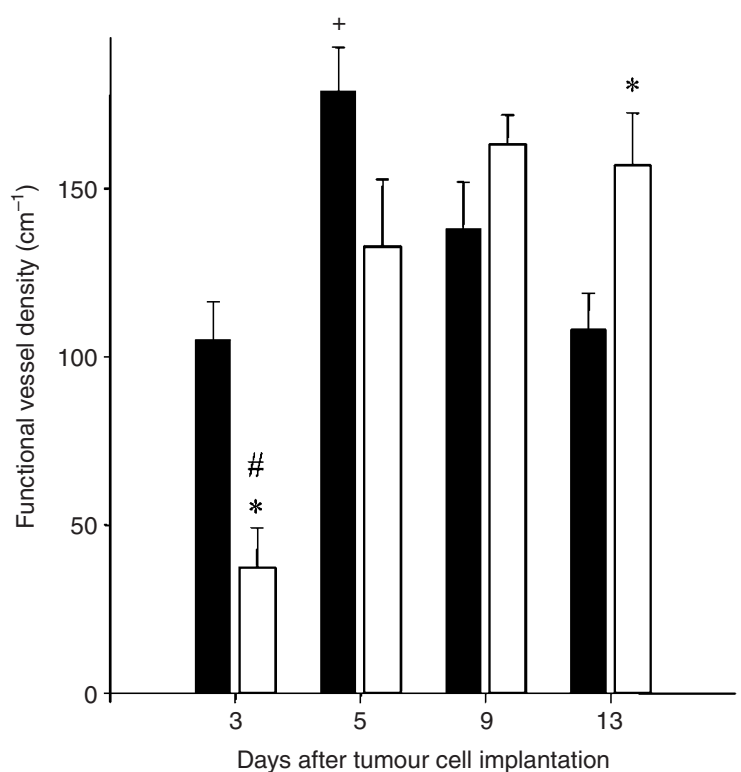

Control group $(n=6)$

$\square$ RGD treated group $(n=6)$

Figure 2 Functional vessel density (mean + s.e.m.) of control group and RGD treated group. Measurements were performed 3, 5, 9 and 13 days after tumour cell implantation by intravital microscopy. Animals were

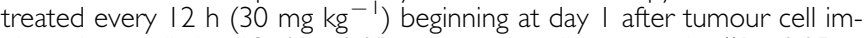
plantation until day $13 . * P<0.05$ vs corresponding controls; $\# P<0.05$ vs day 9 and $13 ;{ }^{+} P<0.05$ vs day 3 and 13 .

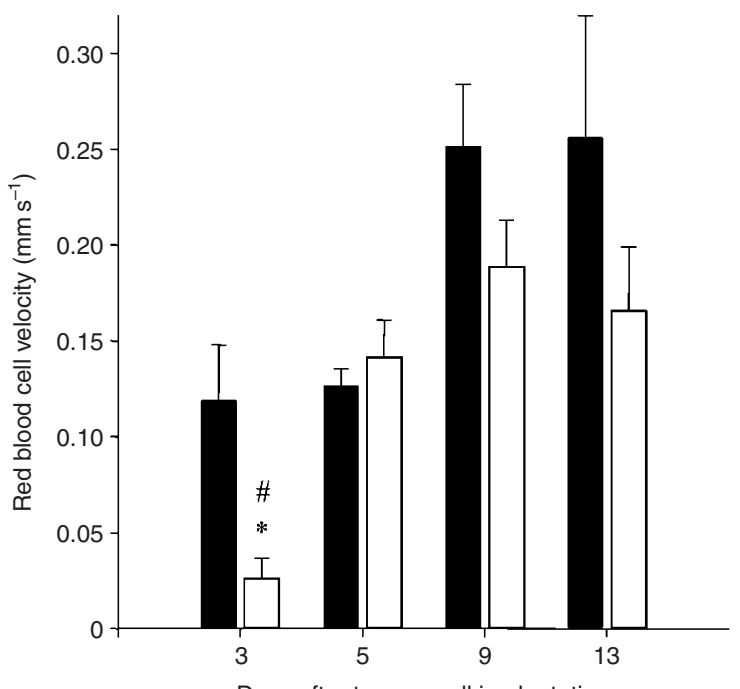

Days after tumour cell implantation

Control group $(n=6)$

$\square$ RGD treated group $(n=6)$

Figure 3 Red blood cell velocity (mean \pm s.e.m.) of control group and RGD treated group. $* P<0.05$ vs corresponding controls; $\# P<0.05$ vs treatment day 9 and day 13.

smaller in comparison to controls on days 7 until 15. As shown in the Kaplan-Meier curve (Figure 8) lymph node metastasis were first palpable in two animals of the control group on day 9. Two days later palpable metastasis was found in all control animals.

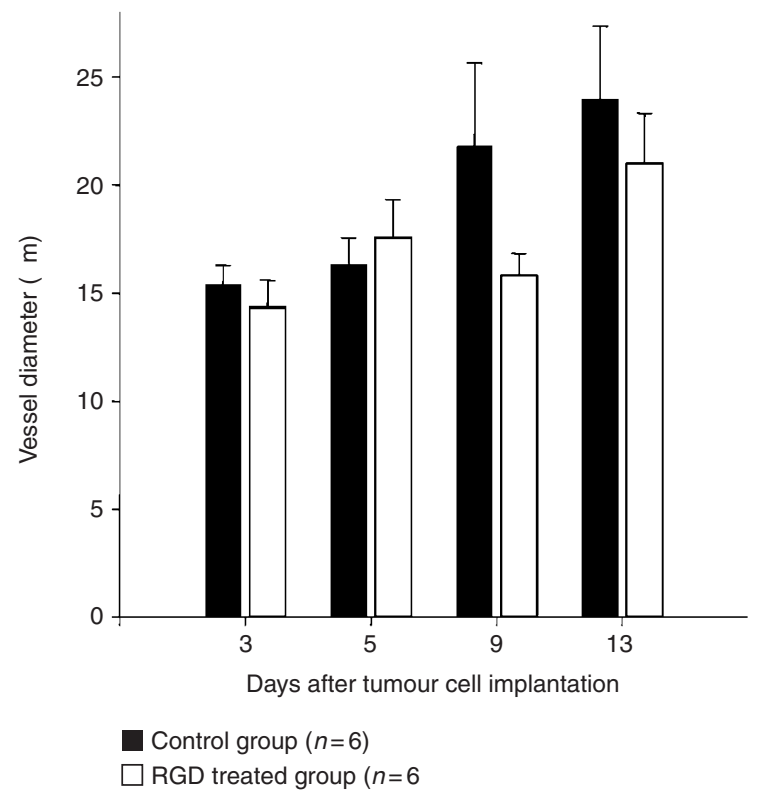

Figure 4 Vessel diameters (mean \pm s.e.m.) as measured by intravital microscopy of control group and RGD treated group.

In contrast, $50 \%$ of the animals treated with RGD peptide were free of metastasis on day 11. It lasted a total of 17 days, 6 days longer than in controls, until the last animal of the anti-angiogenic treated group showed palpable metastasis of this aggressive, very rapidly growing tumour. At the end of the observations when tumour size reached a maximum volume of $7 \mathrm{~cm}$, animals were put to sleep with a high dose of pentobarbital. Metastasis invasion was histologically confirmed from lymph node biopsies.

\section{DISCUSSION}

$\alpha_{\mathrm{v}}$-integrins are receptors for a large number of molecules with an exposed RGD sequence. They are involved in many cell-matrix recognition and cell-adhesion phenomena (Hynes, 1992; Luscinskas and Lawler, 1994). Recent observations revealed that they play an important role in tumour angiogenesis and metastasis (Brooks et al, 1994b; Marshall and Hart, 1996). Cyclic RGD peptides have been developed as selective inhibitors for the $\alpha_{\mathrm{v}}$-integrins (Gurrath et al, 1992; Dechantsreiter et al, 1999). The present study was based on earlier observations showing a potent inhibitory effect on tumour angiogenesis using RGD peptides as $\alpha_{\mathrm{v}}$-Integrin antagonists (Eliceiri and Cheresh, 1999). Our results have shown that treatment with the methylated cyclic RGD-peptide resulted in significant reduction of functional vessel density, associated with retardation of tumour growth and metastasis formation.

\section{Animal model}

It is well known that caution must be exercised in the extrapolation of in vitro observations to the in vivo situation, specially concerning experiments about tumour angiogenesis (Jain et al, 1997). The present tumour model (Fortner et al, 1961; Asaishi et al, 1981; Endrich et al, 1982) was chosen because detailed information and experience is available about microcirculatory and morphologic changes of the amelanotic melanoma A-Mel-3 during tumour angiogenesis and growth. A broad spectrum of knowledge could be gathered for more than 20 years concerning the tumour profile, including features like growth rate, invasion of organ systems, and sensitivity to various therapeutic regimens. The A-Mel-3 is an early 

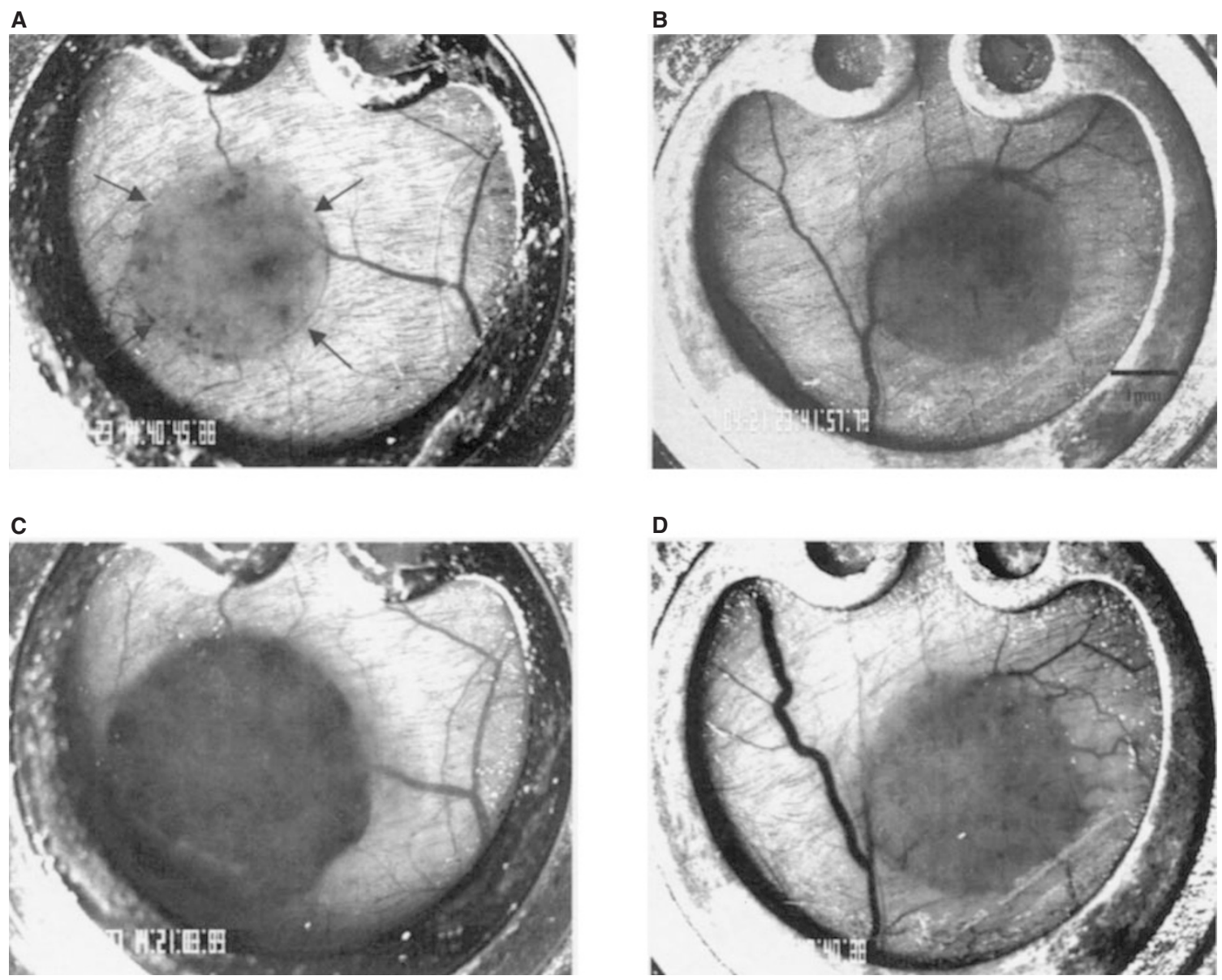

Figure 5 Images of the A-Mel-3 tumour in the dorsal skinfold chamber acquired by video macroscopy. (A) Tumour of control group 5 days after tumour cell implantation. Arrows define the tumour margin. (C) The same tumour 4 days later. (B) Corresponding tumour of RGD treated group on day 5 and (D) same tumour on day 9 after tumour cell implantation. Bar I mm.

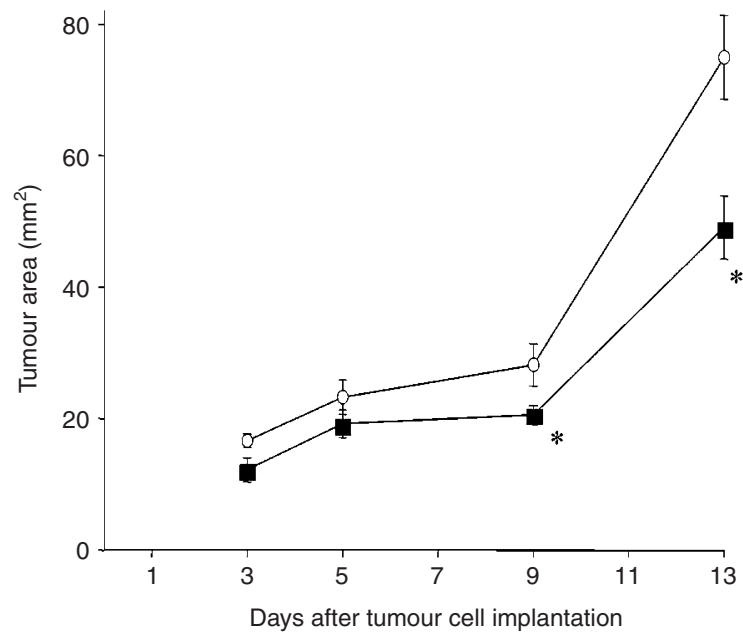

Control group $(n=60$

RGD treated group $(n=6)$

Figure 6 Area of the A-Mel-3 tumour of the control group and the RGD treated group in the dorsal skinfold chamber measured on day 3 , 5,9 and 13 after tumour cell implantation (mean \pm s.e.m.). $* P<0.05$ vs corresponding controls.

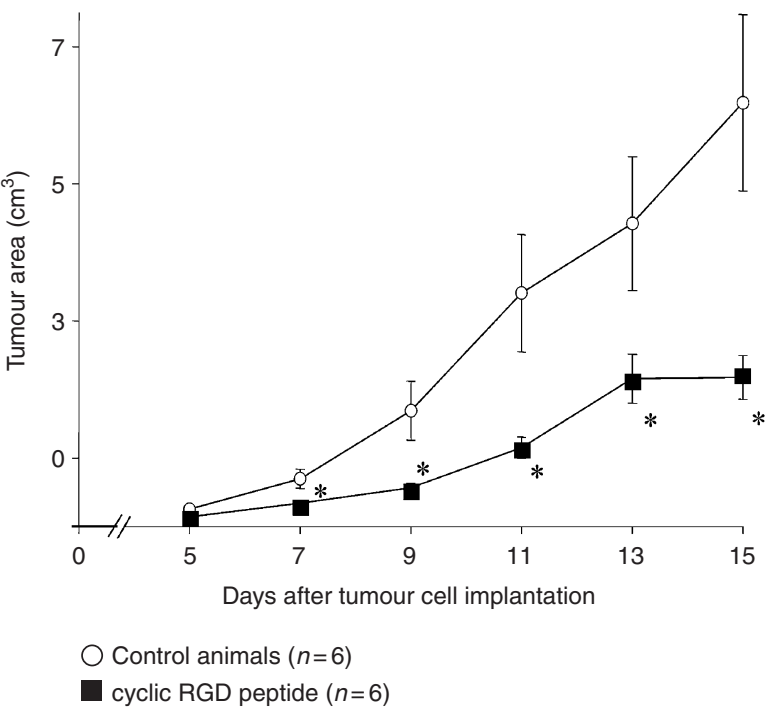

Figure 7 Tumour growth curves of animals with subcutaneously implanted solid A-Mel-3 tumours. Changes in tumour volume are presented for control animals and following application of cyclic RGD peptide. Values are indicated as mean \pm s.e.m. $* P<0.05$ vs controls. 


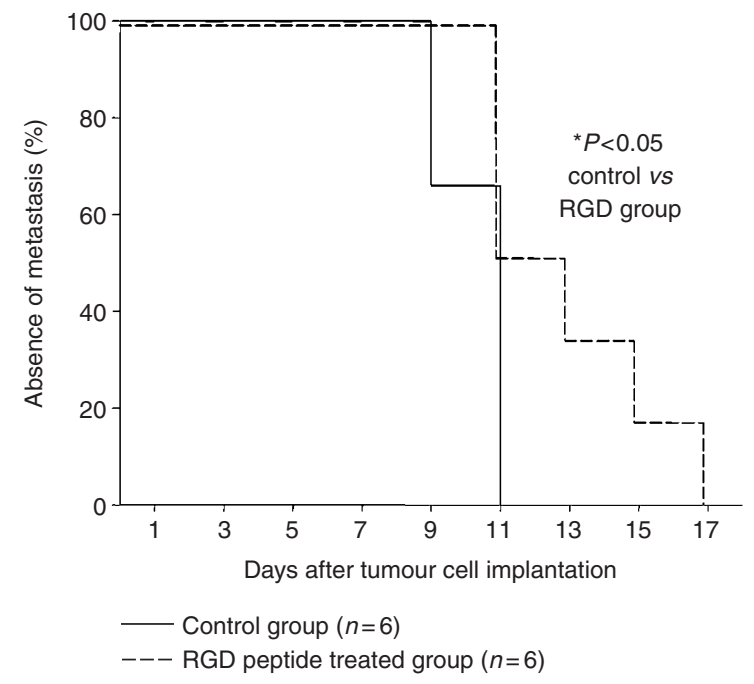

Figure 8 Metastasis formation presented as a Kaplan-Meier curve. Animals of the control group and animals of the RGD peptide treated group were examined for axillar and inguinal lymph node metastases during evaluation of tumour growth. Metastasis formation was significantly delayed following therapy with the RGD peptide. ${ }^{*} P<0.05$ vs controls.

metastasising, exponentially growing aggressive tumour which does not show spontaneous remission. It is therefore suitable for testing the effects of therapeutic modalities. Use of the dorsal skinfold chamber preparation of a solid tumour combined with intravital microscopy and subsequent quantitative microvascular analysis provides an excellent and well established tool for repetitive, direct evaluation of tumour angiogenesis and microcirculation during a long period of anti-angiogenic treatment (Borgstroem et al, 1996; Dellian et al, 1996; Jain et al, 1997; Vajkoczy et al, 2000).

\section{Effects of treatment with RGD-peptides on subcutaneous tumour growth and metastasis}

The growth and metastatic properties of solid tumours are directly influenced by the process of angiogenesis (Folkman, 1990). In early tumour growth, nutrition of tumour cells is guaranteed by diffusion from the environment. Newly formed blood vessels provide the basis for nutrition and spreading of tumour cells, one of the most fearsome aspects of cancer (Fidler and Ellis, 1994). In our experiments subcutaneous tumour growth was nearly exponential in control animals. Treatment with the RGD peptide integrin antagonist resulted in significant delay of tumour growth until the end of the experiments. Furthermore, metastasis formation was inhibited: At the time when lymphatic metastasis was palpable in all control animals, only $50 \%$ of treated animals showed metastasis. It is well known that the risk of metastasis increases with the number and density of tumour vessels (Weidner et al, 1991, 1993) and that growth of metastasis may be angiogenesis dependent as well (Fidler and Ellis, 1994; Saaristo et al, 2000). Furthermore, growth of metastasis and the primary tumour may be connected: Folkman and coworkers demonstrated that some primary tumours inhibit the growth of their metastases by endogenous anti-angiogenic mediators that are released by the primary tumour (O'Reilly et al, 1994). Sckell et al (1998) have shown evidence that anti-angiogenic effects observed at a secondary site correlate with the tumour burden at the primary site. In our study metastases became earliest palpable on day 9 after tumour cell implantation in controls and approximately $50 \%$ of the RGD-treated animals showed metastases with a tumour size comparable to the metastatic control tumour. Former studies with surgical excision of the A-
Mel-3 have demonstrated that this fast growing, well perfused tumour metastasises already prior to day 5 after implantation of tumour cells (Gamarra et al, 1993). Inguinal or axillary metastases become regularly palpable between days 9 and 11 after tumour cell implantation in untreated animals or following local tumour therapy (Dellian et al, 1994). Thus, appearance and growth of metastasis in our tumour model is very closely related to the time after implantation of tumour cells, but less to the tumour burden of the animals. Our data from intravital microscopy revealed already on day 3 an early vascular network in controls making an early spreading of tumour cells possible, whereas the reduced vessel density in the RGD-treated group may decrease the probability of tumour cell spreading. Exact mechanisms of metastasis inhibition by anti- $\alpha_{\mathrm{v}}$ integrin-treatment in this study, however, are unknown. Reduced metastasis formation may be a consequence of (a) inhibition of angiogenesis at the primary tumour site and thus delayed spreading of tumour cells from the primary tumour and (b) inhibition of angiogenesis in the tumour metastasis, resulting in a delay of growth of tumour metastasis.

Based on previous pharmakokinetic studies, anti-angiogenic therapy was performed by intraperitoneal injections of $30 \mathrm{mg} \mathrm{kg}^{-1}$ of the cyclic RGD-peptide twice a day. Plasma half-life time of the cyclic RGD-peptide after intraperitoneal injection was $47 \mathrm{~min}$. However, these data allowed no conclusion on the duration of the peptides' binding to $\alpha_{\mathrm{v}}$-integrins, which may not last the $12 \mathrm{~h}$ until next administration. Remarkably, no side effects were observed in treated animals indicating low toxicity of the therapeutic regiment: Body weight increased similar in control and treated animals, and animals showed normal behaviour without signs of any discomfort.

\section{Effects of treatment with RGD-peptides on functional vessel density and tumour microcirculation}

With our second series of experiments we wanted to address the question whether the inhibitory effect on the subcutaneous tumour growth and metastasis may be attributed to changes in tumour angiogenesis and microcirculation. By intravital microscopy, the activity of angiogenesis in tumour tissue can be most accurately quantified by measurement of functional vessel density (FVD), i.e. the total length of perfused microvessels per unit area of observation (Borgstroem et al, 1996; Dellian et al, 1996; Jain et al, 1997; Vajkoczy et al, 2000).

Comparable to former observations by Endrich et al (1982), FVD of the control group reached a maximum value at day 5 after tumour cell implantation, and decreased thereafter whereas tumours continued to grow. This 'physiological' decline of tumour vessel density in the later growth phases is probably related to malnutrition and onset of necrosis in the tumour centre: Tumour blood vessels are more leaky than are vessels of normal tissues (Gerlowski and Jain, 1986). The increased fluid extravasation leads to an elevated interstitial fluid pressure (IFP) and low perfusion pressure in tumour vessels, mainly in the centre of the tumour (Peters et al, 1980; Wiig et al, 1982). This finally results in hypoxia and necrosis formation of central parts of the melanoma, whereas the tumour margin is still sufficiently supplied with blood (Netti et al, 1999). On that score the data of the RGD treated group showed three remarkable distinctions: (a) the FVD was significantly lower in early angiogenesis; (b) reached the maximum value not before day 9; and (c) thereafter stayed nearly at the same level until the end of the experiments. Vessel growth was especially inhibited and delayed in the early stage of tumour growth on day 3 , whereas differences in tumour growth became first visible later, beginning on day 9 after tumour implantation in the dorsal skinfold chamber, presumably as a consequence of inhibition of angiogenesis. The lack of 'physiological' decline of tumour vessel density observed following anti- $\alpha_{\mathrm{v}}$ integrin-treatment may be related to continuous delay of tumour growth. 
Analysis of red blood velocity during tumour angiogenesis revealed differences only at day 3 following tumour implantation. At this time point, control tumours already exhibited a dense vascular network, whereas in tumours following anti-angiogenic treatment few sprouts as signs of early angiogenesis were visible, which contained erythrocytes, but often no movement of red blood cells was seen yet. In contrast to results of studies of the effects of inhibition of VEGF on tumour microvasculature (Yuan et al, 1995; Borgstroem et al, 1996), vessel diameters were similar in control and treated tumours of the present study and increased at best slightly during tumour growth. These differences are most likely related to the divergent targets of anti-angiogenic therapeutic regimens. Although leucocyte-adhesion is discussed to be relevant for angiogenesis (Folkman and Shing, 1992; Ferrara, 1996), leucocyteendothelium interaction was almost absent in both groups. Thus the known reduced expression of leucocyte adhesion molecules in tumour endothelium (Dellian et al, 1995; Borgstroem et al, 1997) seems to be not affected by anti-angiogenic therapy directed against $\alpha_{\mathrm{v}}$-integrins.

\section{REFERENCES}

Asaishi K, Endrich B, Goetz AE, Messmer K (1981) Quantitative analysis of microvascular structure and function in the amelanotic melanoma AMel-3. Cancer Res 41: $1898-1904$

Atherton A, Born GV (1972) Quantitative investigations of the adhesiveness of circulating polymorphonuclear leucocytes to blood vessel walls. J Physiol (Lond) 222: $447-474$

Auerbach W, Auerbach R (1994) Angiogenesis inhibition: a review. Pharmacol Ther 63: $265-311$

Bayless KJ, Salazar R, Davis GE (2000) RGD-dependent vacuolation and lumen formation observed during endothelial cell morphogenesis in three-dimensional fibrin matrices involves the alpha(v)beta(3) and alpha(5)beta(1) integrins. Am J Pathol 156: 1673-1683

Borgstroem P, Hillan KJ, Sriramarao P, Ferrara N (1996) Complete inhibition of angiogenesis and growth of microtumors by anti-vascular endothelial growth factor neutralizing antibody: novel concepts of angiostatic therapy from intravital videomicroscopy. Cancer Res 56: 4032-4039

Borgstroem P, Hughes GK, Hansell P, Wolitsky BA, Sriramarao P (1997) Leukocyte adhesion in angiogenic blood vessels. Role of E-selectin, P-selectin, and beta2 integrin in lymphotoxin-mediated leukocyte recruitment in tumor microvessels. J Clin Invest 99: 2246-2253

Brooks PC (1996) Role of integrins in angiogenesis. Eur J Cancer 32a: 2423 2429

Brooks PC, Clark RA, Cheresh DA (1994b) Requirement of vascular integrin alpha $\mathrm{v}$ beta 3 for angiogenesis. Science 264: $569-571$

Brooks PC, Montgomery AM, Rosenfeld M, Reisfeld RA, Hu T, Klier G, Cheresh DA (1994a) Integrin alpha v beta 3 antagonists promote tumor regression by inducing apoptosis of angiogenic blood vessels. Cell 79: $1157-1164$

Brooks PC, Silletti S, von Schalscha TL, Friedlander M, Cheresh DA (1998) Disruption of angiogenesis by PEX, a noncatalytic metalloproteinase fragment with integrin binding activity. Cell 92: $391-400$

Brooks PC, Stromblad S, Sanders LC, von Schalscha TL, Aimes RT, Stetler Stevenson WG, Quigley JP, Cheresh DA (1996) Localization of matrix metalloproteinase MMP-2 to the surface of invasive cells by interaction with integrin alpha v beta 3. Cell 85: 683-693

Cheresh DA (1992) Structural and biologic properties of integrin-mediated cell adhesion. Clin Lab Med 12: 217-236

Clark RA, Lanigan JM, DellaPelle P, Manseau E, Dvorak HF, Colvin RB (1982) Fibronectin and fibrin provide a provisional matrix for epidermal cell migration during wound reepithelialization. J Invest Dermatol 79: $264-269$

Dechantsreiter MA, Planker E, Matha B, Lohof E, Hoelzemann G, Jonczyk A, Goodman SL, Kessler H (1999) N-Methylated cyclic RGD peptides as highly active and selective alpha(V)beta(3) integrin antagonists. J Med Chem 42: 3033-3040

Dellian M, Abels C, Kuhnle GE, Goetz AE (1995) Effects of photodynamic therapy on leucocyte-endothelium interaction: differences between normal and tumour tissue. Br J Cancer 72: 1125-1130

\section{CONCLUSIONS}

Inhibition of $\alpha_{\mathrm{v}}$-integrins by a cyclic RGD-peptide resulted in significant reduction of functional vessel density, retardation of tumour growth and metastasis in vivo. The anti-tumor efficacy was associated with remarkable low toxicity of this compound. Administration and dosage of the cyclic RGD-peptide may be further optimised in future studies. Currently, clinical studies are performed to test safety of anti-angiogenic therapy with this cyclic RGD-peptide in humans.

\section{ACKNOWLEDGEMENTS}

We thank Dr Jutta Haunschild, Merck KgaA, Grafing, Germany, for measurement of plasma-pharmakokinetics of cyclic peptides by HPLC. The authors wish to dedicate this publication to Professor Messmer on the occasion of his 65th birthday.

Dellian M, Walenta S, Gamarra F, Kuhnle GE, Mueller Klieser W, Goetz AE (1994) High-energy shock waves enhance hyperthermic response of tumors: effects on blood flow, energy metabolism, and tumor growth. $J$ Natl Cancer Inst 86: $287-293$

Dellian M, Witwer BP, Salehi HA, Yuan F, Jain RK (1996) Quantitation and physiological characterization of angiogenic vessels in mice: effect of basic fibroblast growth factor, vascular endothelial growth factor/vascular permeability factor, and host microenvironment. Am J Pathol 149: 59-71

Eliceiri BP, Cheresh DA (1999) The role of alphav integrins during angiogenesis: insights into potential mechanisms of action and clinical development. J Clin Invest 103: $1227-1230$

Endrich B, Hammersen F, Goetz AE, Messmer K (1982) Microcirculatory blood flow, capillary morphology and local oxygen pressure of the hamster amelanotic melanoma A-Mel-3. J Natl Cancer Inst 68: 475-485

Erdreich-Epstein A, Shimada H, Groshen S, Liu M, Metelitsa LS, Kim KS, Stins MF, Seeger RC, Durden DL (2000) Integrins alpha(v)beta3 and alpha(v)beta5 are expressed by endothelium of high-risk neuroblastoma and their inhibition is associated with increased endogenous ceramide. Cancer Res 60: 712-721

Ferrara N (1996) Natural killer cells, adhesion and tumor angiogenesis. Nat Med 2: $971-972$

Fidler IJ, Ellis LM (1994) The implications of angiogenesis for the biology and therapy of cancer metastasis. Cell 79: $185-188$

Folkman J (1990) What is the evidence that tumors are angiogenesis dependent? J Natl Cancer Inst 82: 4-6

Folkman J (1995) Angiogenesis in cancer, vascular, rheumatoid and other disease. Nat Med 1: $27-31$

Folkman J, Shing Y (1992) Angiogenesis. J Biol Chem 267: 10931 - 10934

Fortner JG, Mahy AG, Schrodt GR (1961) Transplantable tumors of the Syrian (golden) hamster. Part I: Tumors of the alimentary tract, endocrine glands and melanomas. Cancer Res 21: $161-198$

Gamarra F, Spelsberg F, Dellian M, Goetz AE (1993) Complete local tumor remission after therapy with extra-corporeally applied high-energy shock waves (HESW). Int J Cancer 55: 153-156

Gerlowski LE, Jain RK (1986) Microvascular permeability of normal and neoplastic tissues. Microvasc Res 31: 288-305

Graham CH, Rivers J, Kerbel RS, Stankiewicz KS, White WL (1994) Extent of vascularization as a prognostic indicator in thin $(<0.76 \mathrm{~mm})$ malignant melanomas. Am J Pathol 145: 510-514

Gurrath M, Muller G, Kessler H, Aumailley M, Timpl R (1992) Conformation/activity studies of rationally designed potent anti- adhesive RGD peptides. Eur J Biochem 210: $911-921$

Hanahan D, Folkman J (1996) Patterns and emerging mechanisms of the angiogenic switch during tumorigenesis. Cell 86: $353-364$

Hynes RO (1992) Integrins: versatility, modulation, and signaling in cell adhesion. Cell 69: 11-25

Jain RK, Schlenger K, Hoeckel M, Yuan F (1997) Quantitative angiogenesis assays: progress and problems. Nat Med 3: 1203-1208 
Kaplan EL, Meier P (1958) Nonparametric estimation from incomplete observations. J Am Stat Assoc 53: 457-481

Klyscz T, Juenger M, Jung F, Zeintl H (1997) Cap image - a new kind of computer-assisted video image analysis system for dynamic capillary microscopy. Biomed Tech Berl 42: 168-175

Lee ET, Deso MM, Gehan EA (1975) A Monte-Carlo study of the power of some two-sample tests. Biometrika 62: 425-532

Lee ET (1980) Statistical methods for survival data analysis. Lifetime Learning Publications: Belmont

Liotta LA, Steeg PS, Stetler Stevenson WG (1991) Cancer metastasis and angiogenesis: an imbalance of positive and negative regulation. Cell 64: $327-336$

Luscinskas FW, Lawler J (1994) Integrins as dynamic regulators of vascular function. FASEB J 8: 929-938

Marshall JF, Hart IR (1996) The role of alpha v-integrins in tumour progression and metastasis. Semin Cancer Biol 7: 129-138

Netti PA, Hamberg LM, Babich JW, Kierstead D, Graham W, Hunter GJ, Wolf GL, Fischman A, Boucher Y, Jain RK (1999) Enhancement of fluid filtration across tumor vessels: implication for delivery of macromolecules. Proc Natl Acad Sci USA 96: 3137-3142

Nicosia RF, Bonanno E (1991) Inhibition of angiogenesis in vitro by Arg-GlyAsp-containing synthetic peptide. Am J Pathol 138: 829-833

O’Reilly MS, Holmgren L, Shing Y, Chen C, Rosenthal RA, Moses M, Lane WS, Cao Y, Sage EH, Folkman J (1994) Angiostatin: a novel angiogenesis inhibitor that mediates the suppression of metastases by a Lewis lung carcinoma. Cell 79: $315-328$

O’Reilly MS, Boehm T, Shing Y, Fukai N, Vasios G, Lane WS, Flynn E, Birkhead JR, Olsen BR, Folkman J (1997) Endostatin: an endogenous inhibitor of angiogenesis and tumor growth. Cell 88: 277-285

Peters W, Teixeira M, Intaglietta M, Gross JF (1980) Microcirculatory studies in rat mammary carcinoma. I. Transparent chamber method, development of microvasculature, and pressures in tumor vessels. J Natl Cancer Inst 65: $631-642$
Saaristo A, Karpanen T, Alitalo K (2000) Mechanisms of angiogenesis and their use in the inhibition of tumor growth and metastasis. Oncogene 19: $6122-6129$

Sckell A, Safabakhsh N, Dellian M, Jain RK (1998) Primary tumor sizedependent inhibition of angiogenesis at a secondary site: an intravital microscopic study in mice. Cancer Res 58: 5866-5869

Stromblad S, Becker JC, Yebra M, Brooks PC, Cheresh DA (1996) Suppression of p53 activity and p21WAF1/CIP1 expression by vascular cell integrin alphaVbeta3 during angiogenesis. J Clin Invest 98: 426-433

United Kingdom Co-ordinating Committee on Cancer Research (UKCCCR) (1998) Guidelines for the Welfare of Animals in Experimental Neoplasia 2nd edn. Br J Cancer 77: $1-10$

Vajkoczy P, Ullrich A, Menger MD (2000) Intravital fluorescence videomicroscopy to study tumor angiogenesis and microcirculation. Neoplasia 2: $53-61$

Weidner N, Carroll PR, Flax J, Blumenfeld W, Folkman J (1993) Tumor angiogenesis correlates with metastasis in invasive prostate carcinoma. Am J Pathol 143: 401 - 409

Weidner N, Semple JP, Welch WR, Folkman J (1991) Tumor angiogenesis and metastasis correlation in invasive breast carcinoma. $N$ Engl J Med 324: $1-8$

Weiss N, Delius M, Gambihler S, Dirschedl P, Goetz A, Brendel W (1990) Influence of the shock wave application mode on the growth of A-Mel 3 and SSK2 tumors in vivo. Ultrasound Med Biol 16: 595-605

Wiig H, Tveit E, Hultborn R, Reed RK, Weiss L (1982) Interstitial fluid pressure in DMBA-induced rat mammary tumours. Scand J Clin Lab Invest 42: $159-164$

Yuan F, Dellian M, Fukumura D, Leunig M, Berk DA, Torchilin VP, Jain RK (1995) Vascular permeability in a human tumor xenograft: molecular size dependence and cutoff size. Cancer Res 55: 3752-3756

Zeintl H, Sack FU, Intaglietta M, Messmer K (1989) Computer assisted leukocyte adhesion measurement in intravital microscopy. Int J Microcirc Clin Exp 8: 293-302 